\title{
Non-high-density lipoprotein cholesterol may predict the cardio-cerebrovascular risk in patients on maintenance hemodialysis
}

Denggui Luo ${ }^{\dagger}$ Yueming Luo ${ }^{\dagger}$, Yanhong Zou, Yuanzhao Xu, Bo Fu, Dong Yang, Jun Yang, Cai Xu, Shuyi Ling, Shunmin Li ${ }^{*}$ and Airong Qi ${ }^{*}$ (i)

\begin{abstract}
Background: Non-high-density lipoprotein cholesterol (non-HDL-C) may be an independent risk factor for cardiocerebrovascular disease (CVD); however, the cutoff level in patients on maintenance hemodialysis (MHD) is unknown.

Methods: This was a retrospective multicenter study of MHD patients treated at 10 dialysis centers in Guangdong Province from July 1, 2016, to April 1, 2017. Laboratory test data were collected and CVD complications and outcomes recorded.

Results: In total, 1288 eligible patients were included in this study; the non-HDL-C interquartile range was 2.76 (2.24-3.45) $\mathrm{mmol} / \mathrm{L}$. Over a median follow-up time of 24 months, 141 patients developed CVD. The non-HDL-C level was a principal risk factor for such events $(P<0.05 ; 95 \%$ confidence interval $0.800-0.842)$. The maximum Youden index was 0.549 and the best cutoff $>3.39 \mathrm{mmol} / \mathrm{L}$.
\end{abstract}

Conclusion: Higher baseline non-HDL-C levels may increase the CVD risk in MHD patients. Thus, non-HDL-C effectively predicts CVD.

Keywords: Non-LDL-C, Cardio-cerebrovascular risk, Maintenance hemodialysis

\section{Background}

Chronic kidney disease (CKD) is associated with significant morbidity and mortality. In 2017, 1.2 million people worldwide died from CKD [1]. End-stage renal disease (ESRD) has become a major public health problem given increased life expectancies worldwide [2]. More than 2.5 million people are on renal replacement therapy; the number is projected to double by 2030 [3]. Such patients are at high risk of cardio-cerebrovascular disease (CVD), which independently predicts a need for dialysis $[4,5]$. Attempts to reduce CVD in ESRD patients have usually

\footnotetext{
*Correspondence: zyylishunmin@163.com; 81863418@163.com ${ }^{+}$Denggui Luo and Yueming Luo contributed equally to this work. The Fourth Affiliated Hospital of Guangzhou University of Chinese Medicine, Shenzhen Traditional Chinese Medicine Hospital, Shenzhen, China
}

been extensions of strategies employed for general populations [6]. Dyslipidemia in ESRD patients, and frequent changes in lipid and lipoprotein levels, greatly contribute to CVD development [7]. Certain dyslipidemia patterns increase the risk of atherosclerotic vascular disease in general populations. It thus seems likely that dyslipidemia increases the CVD risk in ESRD patients. Such dyslipidemia is characterized by high triglyceride (TG) and low high-density lipoprotein cholesterol (HDL-C) levels [8]. However, prior studies evaluating associations between specific lipid and lipoprotein levels and CKD were limited in terms of scope and generalizability [9]. Although some studies suggested no, or an inverse, association between low-density lipoprotein cholesterol (LDLC) levels and the CVD risk in patients on maintenance

(c) The Author(s). 2021 Open Access This article is licensed under a Creative Commons Attribution 4.0 International License, which permits use, sharing, adaptation, distribution and reproduction in any medium or format, as long as you give appropriate credit to the original author(s) and the source, provide a link to the Creative Commons licence, and indicate if changes were made. The images or other third party material in this article are included in the article's Creative Commons licence, unless indicated otherwise in a credit line to the material. If material is not included in the article's Creative Commons licence and your intended use is not permitted by statutory regulation or exceeds the permitted use, you will need to obtain permission directly from the copyright holder. To view a copy of this licence, visit http://creativecommons.org/licenses/by/4.0/ The Creative Commons Public Domain Dedication waiver (http://creativecommons.org/publicdomain/zero/1.0/) applies to the data made available in this article, unless otherwise stated in a credit line to the data. 
hemodialysis (MHD), the effects of lipid levels remain unknown [10]. This was a multicenter cross-sectional study of 1876 dialysis patients. The trends, and the effects of confounding factors, were validated and adjusted by dividing patients into quartiles $(1 / 4,3 / 4)$. The study seeks to improve the definition and prevention of, and therapy for, dyslipidemia in dialysis patients.

\section{Methods}

\section{Study design and participants}

This retrospective study was conducted at 10 hospitals in southern Guangdong Province. All hospital laboratories complied with the Guangdong Standard Operation Procedure for Blood Purification and had passed the quality and ability tests of the Guangdong Medical Association [11].

Demographic and dialysis-related data were collected using Epidata Entry ver. 3.1.1203.2006. The study included 1876 patients who underwent regular hemodialysis from July 2016 to July 2017. Additional inclusion criteria were: (1) at least 2 dialysis days/ week, and (2) dialysis duration $\geq 3$ months. The exclusion criteria were: (1) missing baseline or follow-up data (especially lipid data), (2) any past CVD event or death within 3 months after inclusion, and/or (3) a tumor (Fig. 1).

\section{Biochemical analysis}

Serum samples were drawn at MHD commencement and analyzed locally. For all patients, the fasting plasma glucose, serum albumin, hemoglobin, potassium, total cholesterol (TC), HDL-C, TG, LDL-C, blood urea nitrogen, uric acid, white blood cell, platelet, creatinine, calcium, phosphate, and parathyroid hormone (PTH) levels, and the parameter Kt/V (a measure of the efficacy of hemodialysis), were measured at regular but different intervals. The body mass index (BMI) for each patient was calculated as the post-dialysis body weight divided by the square of the height.

\section{Data collection and measures}

General information, medical histories, and laboratory data were collected by physicians. All CVD complications were diagnosed by specialists at each center by reference to the symptoms and signs at onset, and laboratory and imaging data; the latter included coronary angiography, brain computed tomography $(\mathrm{CT})$, and brain magnetic resonance imaging (MRI). The data were stored in Excel format. The study adhered to the principles of the Declaration of Helsinki. The work was approved by the Human Research Ethics Committees of the involved hospitals. Investigators or persons authorized by the investigators explained the benefits and risks of trial participation to each patient, or their legal representatives or notaries. Trial data were stored in a safe in the office of the first author, who performed all statistical analyses.

\section{Baseline and outcome data}

Patient sex, age, and independence (or not) were recorded. Outcomes were assessed from baseline until

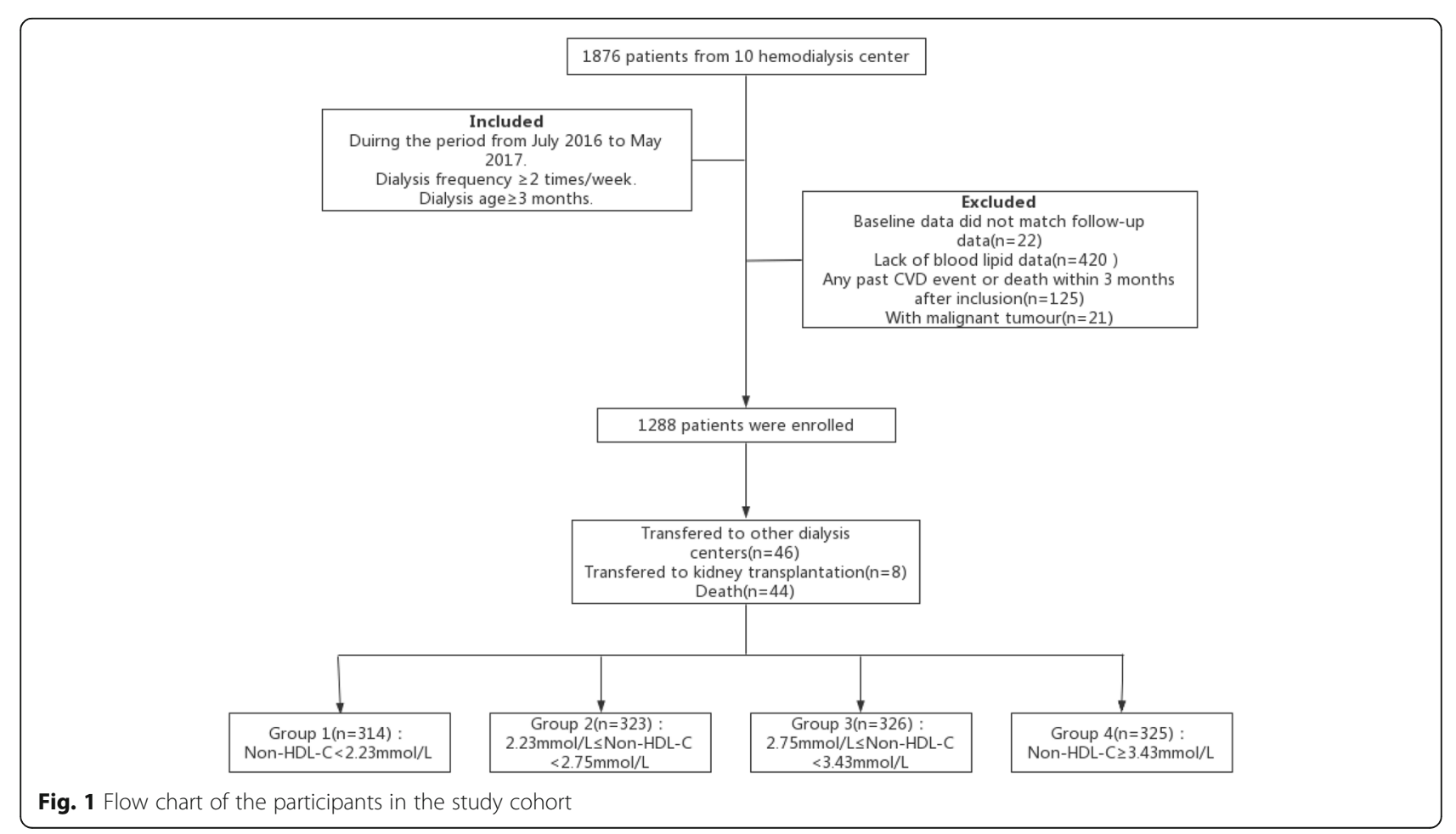


discharge (i.e., the end of intervention) (Table 1). The primary outcomes were CVDs, including myocardial infarction, acute left heart failure, non-myocardial acute coronary syndrome, cerebral infarction, and cerebral hemorrhage. The pre-specified secondary outcomes were the association of the non-HDL-C level with CVD and the predictive utilities of the LDL-C, TC, and non-HDL$C$ levels.

Table 1 Baseline MHD patient characteristics according to Non-HDL-C quartile

\begin{tabular}{|c|c|c|c|c|c|}
\hline \multirow[t]{3}{*}{ Characteristic } & \multicolumn{4}{|l|}{ Non-HDL-C Quartile } & \multirow{3}{*}{$\begin{array}{l}p \text { - } \\
\text { value }\end{array}$} \\
\hline & $\mathrm{Q} 1<2.24$ & $2.24 \leq \mathrm{Q} 2<2.76$ & $2.76 \leq \mathrm{Q} 3<3.45$ & $\mathrm{Q} 4 \geq 3.45$ & \\
\hline & $n=314$ & $n=323$ & $n=326$ & $n=325$ & \\
\hline Age (years) & $57.89 \pm 14.17$ & $59.84 \pm 15.09$ & $59.47 \pm 15.51$ & $62.86 \pm 15.07$ & $<0.001$ \\
\hline Gender & & & & & 0.469 \\
\hline male, n (\%) & 185(58.9\%) & 194(60.1\%) & $184(56.4 \%)$ & $203(62.5 \%)$ & \\
\hline female, $n(\%)$ & $129(41.1 \%)$ & 129(39.9\%) & $142(43.6 \%)$ & $122(37.5 \%)$ & \\
\hline Dialysis time (months) & $28.11(14.09-65.67)$ & $25.17(11.56-53.33)$ & $23.90(9.50-50.40)$ & $26.47(7.99-47.01)$ & \\
\hline BMI (kg/m2) & $19.71(14.50-25.00)$ & $19.71(0.00-23.55)$ & $19.59(0.00-24.72)$ & $22.52(16.51-27.77)$ & $<0.001$ \\
\hline Cause of ESRD, n (\%) & & & & & $<0.001$ \\
\hline primary glomerulonephritis & $177(56.4 \%)$ & $161(50.0 \%)$ & $164(50.5 \%)$ & $120(36.9 \%)$ & \\
\hline diabetic nephropathy & $65(20.7 \%)$ & $68(21.1 \%)$ & $68(20.9 \%)$ & $87(26.8 \%)$ & \\
\hline hypertensive nephropathy & $19(6.1 \%)$ & $12(3.7 \%)$ & $12(3.7 \%)$ & $18(5.5 \%)$ & \\
\hline Anticoagulant type, n (\%) & & & & & 0.136 \\
\hline low molecular weight heparin & $282(89.8 \%)$ & $274(84.8 \%)$ & $276(84.9 \%)$ & $271(83.4 \%)$ & \\
\hline unfractionated heparin & $30(9.6 \%)$ & $42(13.0 \%)$ & $41(12.6 \%)$ & $42(12.9 \%)$ & \\
\hline Dialysis vascular access, n (\%) & & & & & 0.033 \\
\hline AVF & $268(85.4 \%)$ & $277(85.8 \%)$ & $278(85.3 \%)$ & $262(80.6 \%)$ & \\
\hline AVG & $3(1.0 \%)$ & $2(0.6 \%)$ & $6(1.8 \%)$ & $6(1.8 \%)$ & \\
\hline TCC & $30(9.6 \%)$ & $37(11.5 \%)$ & $24(7.4 \%)$ & $31(9.5 \%)$ & \\
\hline NCC & $13(4.1 \%)$ & $7(2.2 \%)$ & $18(5.5 \%)$ & $26(8.0 \%)$ & \\
\hline Mean UFV(L) & $2.43(1.93-3.00)$ & $2.40(1.65-2.93)$ & $2.23(1.66-2.84)$ & $2.30(1.71-3.16)$ & 0.788 \\
\hline Systolic pressure $(\mathrm{mmHg})$ & $146.35 \pm 18.99$ & $145.72 \pm 21.37$ & $146.71 \pm 20.86$ & $145.37 \pm 20.77$ & 0.838 \\
\hline Diastolic pressure $(\mathrm{mmHg})$ & $82.84 \pm 11.89$ & $82.50 \pm 12.49$ & $84.68 \pm 50.09$ & $84.17 \pm 40.21$ & 0.814 \\
\hline Diabetes, n (\%) & $59(18.8 \%)$ & $63(19.5 \%)$ & $77(23.7 \%)$ & $71(21.8 \%)$ & 0.404 \\
\hline FPG (mmol/L) & $4.35 \pm 1.81$ & $6.99 \pm 3.02$ & $4.86 \pm 1.25$ & $7.42 \pm 2.84$ & 0.058 \\
\hline Tc $(\mathrm{mmol} / \mathrm{L})$ & $4.40 \pm 1.28$ & $3.87 \pm 0.42$ & $5.20 \pm 1.25$ & $5.32 \pm 0.24$ & $<0.001$ \\
\hline $\operatorname{Tg}(\mathrm{mmol} / \mathrm{L})$ & $3.36 \pm 2.85$ & $0.81 \pm 0.25$ & $1.67 \pm 1.55$ & $3.09 \pm 2.75$ & $<0.001$ \\
\hline LDL-C (mmol/L) & $2.88(2.40-3.70)$ & $2.06(1.83-2.33)$ & 1.69(1.39-2.66) & $2.02(1.54-2.41)$ & $<0.001$ \\
\hline $\mathrm{HDL}-\mathrm{C}(\mathrm{mmol} / \mathrm{L})$ & $1.14(0.92-1.44)$ & $1.08(0.88-1.27)$ & $1.07(0.88-1.34)$ & $1.07(0.85-1.42)$ & 0.052 \\
\hline Alb (g/L) & $22.04 \pm 17.71$ & $42.75 \pm 1.89$ & $31.74 \pm 16.65$ & $37.75 \pm 3.09$ & $<0.001$ \\
\hline $\mathrm{Cr}(\mu \mathrm{mol} / \mathrm{L})$ & $554.36 \pm 563.53$ & $1082.75 \pm 161.16$ & $937.10 \pm 654.46$ & $1194.25 \pm 307.89$ & $<0.001$ \\
\hline BUN $(\mu \mathrm{mol} / \mathrm{L})$ & $27.18(22.64-34.00)$ & $27.40(22.80-33.90)$ & $26.18(22.18-32.43)$ & $26.97(22.00-34.12)$ & 0.638 \\
\hline $\mathrm{Ua}(\mu \mathrm{mol} / \mathrm{L})$ & $266.60 \pm 211.82$ & $458.75 \pm 35.85$ & $465.30 \pm 271.41$ & $547.25 \pm 133.98$ & $<0.001$ \\
\hline Total Kt/N & $1.33(1.12-1.60)$ & $1.32(1.18-1.50)$ & $1.32(1.18-1.48)$ & $1.37(1.12-1.76)$ & 0.029 \\
\hline WBC $\left(10^{9} / L\right)$ & $4.72 \pm 1.44$ & $6.40 \pm 1.45$ & $6.15 \pm 2.53$ & $7.00 \pm 1.31$ & 0.035 \\
\hline $\mathrm{Hb}(\mathrm{g} / \mathrm{L})$ & $128.27 \pm 34.91$ & $99.00 \pm 12.02$ & $107.00 \pm 41.59$ & $90.25 \pm 26.53$ & $<0.001$ \\
\hline Plt $\left(10^{9} / \mathrm{L}\right)$ & $131.90 \pm 51.11$ & $23.17 \pm 2.92$ & $30.83 \pm 22.22$ & $24.84 \pm 4.37$ & $<0.001$ \\
\hline $\mathrm{K}(\mathrm{mmol} / \mathrm{L})$ & $5.31(4.62-6.40)$ & $5.15(4.50-5.70)$ & $5.05(4.60-5.62)$ & $5.40(4.63-7.00)$ & 0.084 \\
\hline $\mathrm{Ca}(\mathrm{mmol} / \mathrm{L})$ & $2.20(2.08-2.36)$ & $2.16(2.00-2.32)$ & $2.15(2.04-2.31)$ & $2.31(2.12-2.76)$ & 0.012 \\
\hline PTH (pg/ml) & $167.60(38.65-403.60)$ & 260.96(75.05-585.33) & $234.41(72.90-624.25)$ & $233.93(79.03-587.40)$ & 0.009 \\
\hline $\mathrm{P}(\mathrm{mmol} / \mathrm{L})$ & $6.80 \pm 5.89$ & $1.79 \pm 0.47$ & $3.56 \pm 2.83$ & $2.46 \pm 0.44$ & $<0.001$ \\
\hline
\end{tabular}

Values are expressed as mean $\pm S D$, median and interquartile range, or number (percentage) as appropriate. $B M I$ Body mass index, ESRD End-stage renal disease, AVF Autogenous arteriovenous fistula, AVG Arteriovenous graft, TCC Tunnel-cuffed catheter, NCC Non-cuffed catheter, UFV Ultrafiltration volume, CVD Cardiovascular disease, FPG Fasting plasma glucose, TC Total cholesterol, Tg Triglycerides, LDL-c Low density lipoprotein cholesterol, HDL-C High-density lipoprotein cholesterol, Alb Albumin, Cr Creatinine, BUN Blood urea nitrogen, Ua Uric acid, Hb Hemoglobin, Plt Platelets, Pth Parathyroid hormone 


\section{Statistical analyses}

All patients were divided into four groups by reference to the baseline non-HDL-C quartiles. SPSS software (Version 25.0; Chicago, IL, USA) and MedCalc software (Version 16.8; Ostend, Belgium) were used for all analyses. Continuous variables that were normally distributed are given as ${ }^{-} \mathrm{x} \pm s$ and a one-way ANOVA was used for comparisons. Continuous variables that were not normally distributed are shown as medians (quartiles 1 , 3 ) and compared with the aid of the Kruskal-Wallis test. Categorical variables are expressed as frequencies (proportions) and were compared using the chi-squared test. The cumulative survival rate was calculated by the Kaplan-Meier method; survival curves were plotted. The log-rank test was used to test significance. The relationship between the non-HDL-C level and CVDs was analyzed via Cox's proportional hazard regression and the results expressed as hazard ratios (HRs) with 95\% confidence intervals (CIs). The area under the receiver operator curve (AUC) and the 95\% CI were used to evaluate the predictive utility of the non-HDL-C level in terms of various endpoints. The AUC ranged from 0.5 (indicating randomness) to 1.0 (complete dependence). The maximum Youden index was used to determine the optimal non-HDL-C cutoff for each endpoint. A two-sided $\alpha \leq$ 0.05 was taken to indicate significance.

\section{Results}

\section{Participant characteristics}

Ultimately, a total of 1288 patients aged $59.85 \pm 15.06$ years were enrolled; 766 males $(59.5 \%)$ and 522 females (40.5\%). The non-HDL-C interquartile range was 2.76 (2.24-3.45) $\mathrm{mmol} / \mathrm{L}$. Age; pre-dialysis weight; and the levels of white and red blood cells and platelets, serum creatinine and albumin, ferritin, and blood calcium differed among the four quartiles (all $P<0.05$ ). The median follow-up time was 24 months. During this time, 141 (10.94\%) patients experienced CVD for the first time, including 39 (3.02\%) with acute myocardial infarctions, 32 $(2.48 \%)$ with cerebral infarctions, 55 (4.27\%) with intracerebral hemorrhages, and 15 (1.16\%) with acute coronary syndromes (Table 2). Patients in the non-HDL$\mathrm{C} \geq 3.45 \mathrm{mmol} / \mathrm{L}$ group exhibited a higher CVD rate (31.7\%) than the other groups (Fig. 2). Univariate Cox's regression showed that age and the levels of white blood cells, platelets, blood glucose, TC, TG, non-HDL-C, and total blood protein were risk factors for CVD (all $P<$ 0.05, Tables 3 and 4). The Kaplan-Meier survival curve revealed a positive correlation between the non-HDL-C level and CVD incidence $(P<0.01$; Fig. 3$)$. The ROC curves suggested that, compared to the TC (AUC 0.710, 95\% CI 0.684-0.735), TG (AUC 0.777, 95\% CI $0.753-$ 0.799), and LDL-C (AUC 0.583, 95\% CI 0.753-0.799) levels, the non-HDL-C level (AUC 0.822, 95\% CI 0.8000.842 ) better predicted CVD (Fig. 4). The maximum Youden index was 0.549 , and the corresponding nonHDL-C cutoff $3.39 \mathrm{mmol} / \mathrm{L}$. Next, the non-HDL-C level was included in a Cox regression using the quartiles as categorical variables. Single-factor regression showed that, after adjusting for age and sex using the Q1 group as a reference, Q2 $(P<0.01)$, Q3 $(P<0.01)$, and Q4 $(P<$ $0.01)$ were at higher risks of CVD; the risks were not affected by diabetes status, dialysis duration, BMI, anticoagulant type, or systolic or diastolic blood pressure. After further adjustment for hemoglobin, serum albumin, and blood uric acid and creatinine levels, the Kt/V, average ultrafiltration rate, and platelet and serum urea nitrogen levels, the risk proportions remained different (and statistically significant) $(P<0.01$, Table 4$)$. Therefore, the non-HDL-C level was associated with an increased risk of cardiovascular disease in MHD patients.

\section{Discussion}

Hypercholesterolemia is an independent risk factor for coronary heart disease (CHD) and LDL-C is the principal laboratory parameter used for CVD management [12]. The experts of the National Lipid Association concluded that increased non-HDL-C and LDL-C levels were the root causes of atherosclerosis because they are involved in the majority of clinical CHD events $[13,14]$.

Table 2 New-onset CVD events during a median 24 months follow-up in patients undergoing haemodialysis stratified according to Non-HDL-C quartile

\begin{tabular}{|c|c|c|c|c|c|}
\hline \multirow[t]{3}{*}{ Event } & \multicolumn{5}{|c|}{ Patient groups based on Non-HDL-C levels } \\
\hline & $\mathrm{Q} 1<2.24$ & $2.24 \leq \mathrm{Q} 2<2.76$ & $2.76 \leq \mathrm{Q} 3<3.45$ & $\mathrm{Q} 4 \geq 3.45$ & \\
\hline & $n=314$ & $n=323$ & $n=326$ & $n=325$ & $p$-value \\
\hline Total CVD events & $6(4.3 \%)$ & $9(6.4 \%)$ & $23(16.3 \%)$ & 103(73.0\%) & \multirow[t]{5}{*}{0.029} \\
\hline Myocardial infarction & $0(0.0 \%)$ & $1(0.7 \%)$ & $6(4.3 \%)$ & $32(22.7 \%)$ & \\
\hline Cerebral infarction & $3(2.1 \%)$ & $5(3.5 \%)$ & $8(5.7 \%)$ & $16(11.3 \%)$ & \\
\hline Cerebral haemorrhage & $1(0.7 \%)$ & $2(1.4 \%)$ & $7(5.0 \%)$ & 45(31.9\%) & \\
\hline Acute coronary syndrome & $2(1.4 \%)$ & $1(0.7 \%)$ & $2(1.4 \%)$ & $10(7.1 \%)$ & \\
\hline
\end{tabular}

Data presented as $\mathrm{n}$ of patients (\%)

$\mathrm{X}$ 2-test was used for the comparison among the four groups 


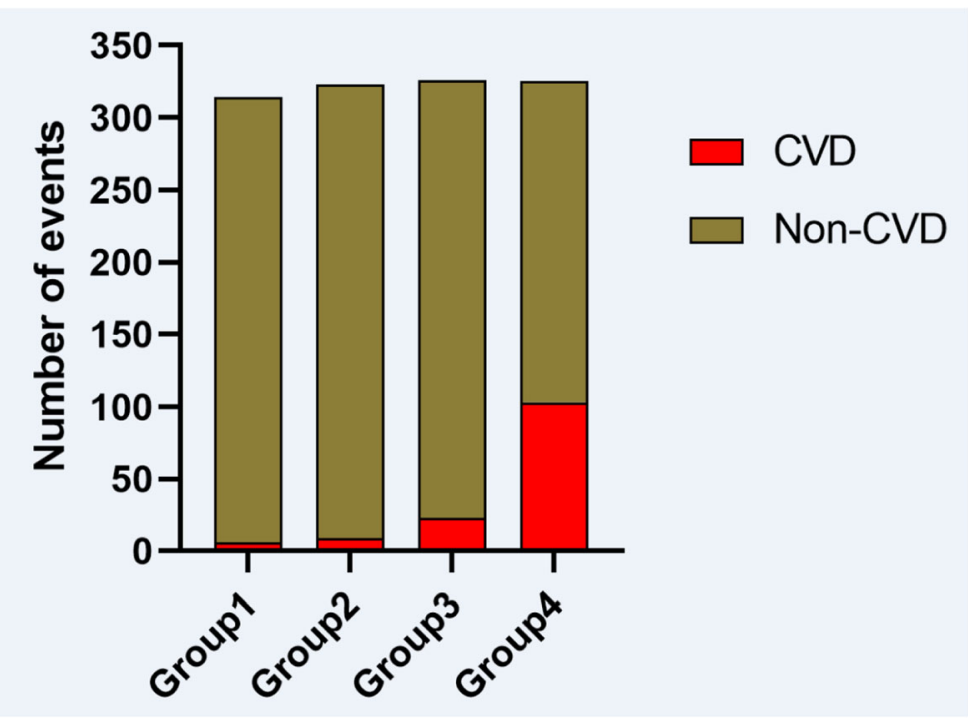

Fig. 2 The comparison of CVD events between each group

Table 3 The association of Non-HDL-C with CVD in the study cohort

\begin{tabular}{|c|c|c|c|c|}
\hline \multirow[t]{2}{*}{ Variable } & \multicolumn{2}{|l|}{ Univariate analysis } & \multicolumn{2}{|c|}{ Multivariate analysis } \\
\hline & $H R(95 \% C l)$ & $P$-value & $H R(95 \% \mathrm{Cl})$ & $P$-value \\
\hline Age & $1.022(1.011-1.034)$ & $<0.001$ & $1.020(1.009-1.032)$ & $<0.001$ \\
\hline Gender & $0.938(0.665-1.323)$ & 0.714 & & \\
\hline BMI & $0.992(0.981-1.004)$ & 0.196 & & \\
\hline Total KTN & $0.989(0.977-1.002)$ & 0.098 & & \\
\hline WBC & $1.078(1.044-1.114)$ & $<0.001$ & $1.083(1.040-1.128)$ & $<0.001$ \\
\hline Plt & $1.005(1.003-1.007)$ & $<0.001$ & $1.005(1.002-1.007)$ & $<0.001$ \\
\hline $\mathrm{Hb}$ & $1.000(0.997-1.004)$ & 0.952 & & \\
\hline FPG & $1.037(1.007-1.067)$ & 0.015 & $1.026(0.999-1.054)$ & 0.061 \\
\hline K & $0.996(0.989-1.003)$ & 0.996 & & \\
\hline $\mathrm{Ca}$ & $0.996(0.989-1.003)$ & 0.278 & & \\
\hline$P$ & $0.983(0.912-1.060)$ & 0.664 & & \\
\hline Ua & $1.001(1.000-1.002)$ & 0.057 & & \\
\hline $\mathrm{Cr}$ & $1.000(1.000-1.001)$ & 0.303 & & \\
\hline Alb & $1.008(0.990-1.026)$ & 0.380 & & \\
\hline Tc & $1.053(1.020-1.087)$ & 0.002 & & \\
\hline $\operatorname{Tg}$ & $1.080(1.049-1.111)$ & $<0.001$ & $1.094(1.056-1.133)$ & $<0.001$ \\
\hline LDL-C & $0.996(0.991-1.002)$ & 0.194 & & \\
\hline HDL-C & $0.068(0.038-0.120)$ & $<0.001$ & & \\
\hline Non-HDL-C & $1.092(1.061-1.124)$ & $<0.001$ & $1.124(1.087-1.161)$ & $<0.001$ \\
\hline Diabetes & $1.048(0.702-1.563)$ & 0.819 & & \\
\hline
\end{tabular}

To reduce the risk of ischemic events in patients with $\mathrm{CHD}$, the fasting LDL-C level should be controlled to $<1.4 \mathrm{mmol} / \mathrm{L}$ (primary goal) and the non-HDL-C level to $<2.2 \mathrm{mmol} / \mathrm{L}$ (secondary goal), according to the 2019 European Guide for the Year [15].

Serum LDL-C, TG, HDL-C, and non-HDL-C levels are associated with the risk of atherosclerotic CVD and other CV events $[13,14]$. Serum $\beta$-trace protein and $\beta 2$-microglobulin, and a composite of these markers with the eGFRcr and eGFRcys rates, were also independently associated with the risk of ESRD and all-cause mortality [16].

The non-HDL-C level is obtained by subtracting the HDL-C level from the TC level, and serves as a comprehensive indicator of the level of atherosclerotic lipids, including LDL-C, lipoprotein A (ApoA), intermediatedensity lipoprotein (IDL), and very low-density lipoprotein (VLDL) remnants [17]; and as a marker of cardiovascular risk [18]. In 2018, the global agestandardized mean non-HD-C level was $3.3 \mathrm{mmol} / \mathrm{L}$ (range $3.2-3.4 \mathrm{mmol} / \mathrm{L}$ ) for women and $3.3 \mathrm{mmol} / \mathrm{L}$ (range 3.3-3.4 mmol/L) for men [19], but the figures for dialysis patients remain unclear.

Over a median follow-up of 24 months, 141 patients suffered from CVD. Univariate Cox's regression showed that age; anticoagulant type; and white blood cell, platelet, blood sugar, TC, TG, non-HDL-C, and total blood protein levels were risk factors for CVD (all $P<0.05$ ). The Kaplan-Meier survival curve revealed a positive correlation between the non-HDL-C level and CVD incidence. The ROC curves suggest that, relative to TC, TG, LDL-C, and other indicators, non-HDL-C better predicted CVD in MHD patients. The Youden index 
Table 4 Cox regression analysis of different levels of Non-HDL-C and cardiovascular and cerebrovascular events

\begin{tabular}{|c|c|c|c|c|c|c|}
\hline \multirow[t]{2}{*}{ Variable } & \multicolumn{2}{|l|}{ Model 1} & \multicolumn{2}{|l|}{ Model 2} & \multicolumn{2}{|l|}{ Model 3} \\
\hline & $H R(95 \% C l)$ & P-value & $H R(95 \% C l)$ & P-value & $H R(95 \% \mathrm{Cl})$ & $P$-value \\
\hline \multicolumn{7}{|c|}{ Continuous variable } \\
\hline Non-HDL-C & $1.102(1.070-1.134)$ & $<0.001$ & $1.135(1.094-1.177)$ & $<0.001$ & $1.266(1.020-1.572)$ & 0.033 \\
\hline \multicolumn{7}{|c|}{ Categorical variables } \\
\hline Q1 & Reference & & Reference & & Reference & \\
\hline Q2 & $0.041(0.018-0.094)$ & $<0.001$ & $0.036(0.016-0.084)$ & $<0.001$ & $0.023(0.003-0.176)$ & $<0.001$ \\
\hline Q3 & $0.070(0.035-0.138)$ & $<0.001$ & $0.060(0.030-0.119)$ & $<0.001$ & $0.056(0.013-0.246)$ & $<0.001$ \\
\hline Q4 & $0.224(0.142-0.354)$ & $<0.001$ & $0.175(0.109-0.282)$ & $<0.001$ & $0.238(0.104-0.545)$ & 0.001 \\
\hline
\end{tabular}

Model 1: Adjusted for age and gender

Model 2: Adjusted for model 1 covariates and diabetes, dialysis time, BMI, anticoagulant type, systolic blood pressure and diastolic pressure Model 3: Adjusted for model 2 covariates and hemoglobin, serum albumin, uric acid, serum $\mathrm{Cr}$, Kt/N, Mean UFV, Platelets, Blood urea nitrogen All variables with a confirmed $P$-value $<0.05$

maximum was 0.549 , corresponding to a non-HDL-C cutoff of $3.39 \mathrm{mmol} / \mathrm{L}$.

Compared to overseas large-scale studies [20], the LDL-C reductions that we observed were greater. Takahiro [21] found that the non-HDL-C levels predicted mortality and was minimally affected by the fasting or serum TG level. Meta-analyses and large prospective studies found that non-HDL-C levels at treatment were better predictors of CVD than the LDL-C levels [22]. The non-HDL-C level is a simple predictor of risk in patients using or discontinuing statins; there is no need for a fasting blood sample [23]. When post-prandial LDL-C and non-HDL-C goals were reassessed using the nonfasting cut-off points, the percentage attainments did not differ in the fasting and non-fasting states. It has been suggested that the control of non-HDL-C levels of afforded better clinical benefits than those delivered by the control of LDL-C levels [24]. Non-HDL-C assessment is better than LDL-C evaluation when exploring the percentage attainments of non-fasting lipid levels that improve the coronary health of dialysis patients
[25]. Cesaro et al. [26] found that ApoA was an independent risk factor for CVD events, but clinical verification is lacking. Unfortunately, ApoA data were lacking in this study; such data are required in future studies.

\section{Study strengths and limitations}

The strengths of the study include the large sample size and the involvement of 10 provincial dialysis centers; this enhances the generalizability of the findings. Also, all researchers strictly followed standard operating procedures. Transdermal dialysis was simple, associated with good patient acceptance. The dropout rate was only $3.5 \%$ and the exit rate $4.0 \%$. The principal limitation is that the retrospective design may be associated with observer and/or performance bias; also, the follow-up time was short. A long-term, multi-center prospective study is required.

\section{Conclusions}

In conclusion, this study found that the serum nonHDL-C levels correlated positively with the

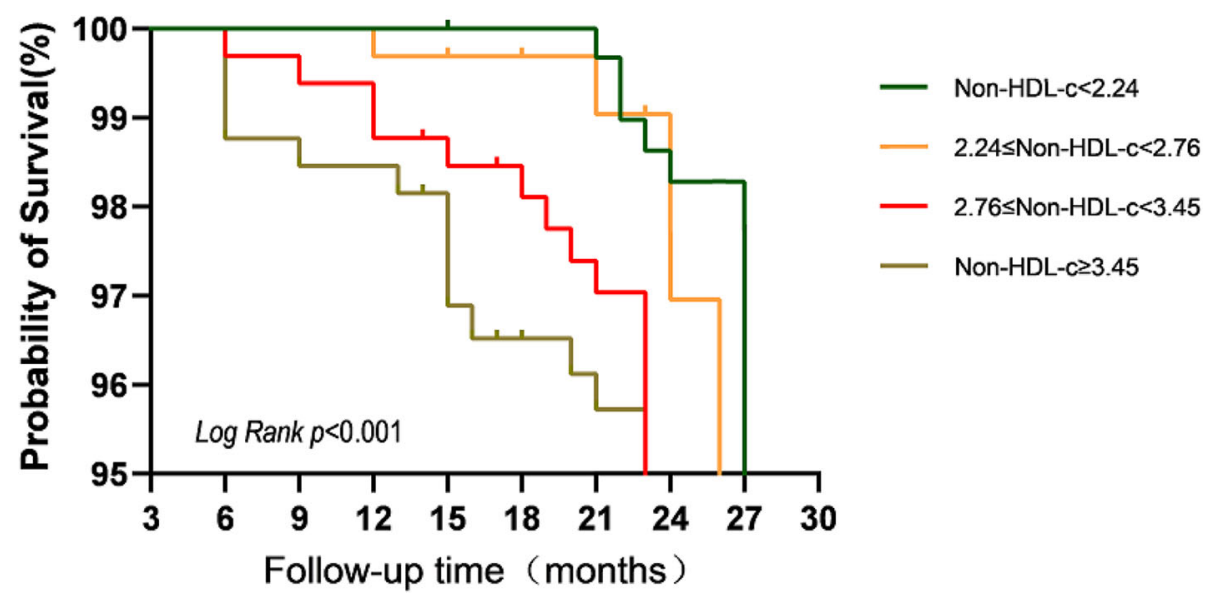

Fig. 3 Kaplan-Meier curves of MHD patients with different levels of Non-HDL-C cardiovascular mortality 


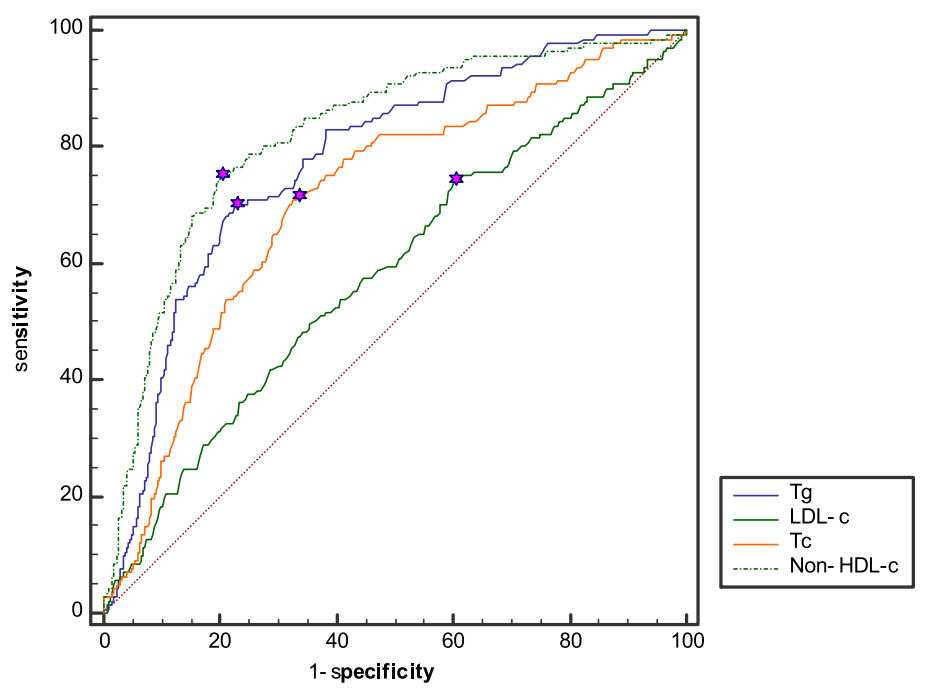

\begin{tabular}{|c|c|c|c|}
\hline Variable & AUC & SE & $95 \% \mathrm{Cl}$ \\
\hline Tg & 0.777 & 0.0198 & $0.753-0.799$ \\
LDL-c & 0.583 & 0.0262 & $0.555-0.610$ \\
Tc & 0.710 & 0.0228 & $0.684-0.735$ \\
\hline Non-HDL-c & 0.822 & 0.0188 & $0.800-0.842$ \\
\hline
\end{tabular}

Fig. 4 ROC curve chart of the predictive effect of $L D L-C, T C$ and Non-HDL-C on CVD events in MHD patients

cardiovascular disease risk. Compared to the TG, TC, and LDL-C levels, the non-HDL-C level better predicted CVD events in MHD patients, and can thus serve as a new clinical marker. Physicians should closely monitor non-HDL-C levels to reduce CVD events in MHD patients.

\section{Acknowledgements}

We would like to thank the members of the Southern Guangdong: Improving Outcome of Kidney Disease (SOGOOD) group: Zongpei Jiang (Department of Nephrology, The Sixth Affiliated Hospital, Sun Yat-Sen University): Guoliang Xiong (The Fourth Affiliated Hospital of Guangzhou University of Chinese Medicine, Shenzhen Traditional Chinese Medicine Hospital, Shenzhen); Guohui Liu (Department of Nephrology, Dongguan people's Hospital, Guangdong, China); Yuping Chen (Department of Nephrology, The First people's Hospital of Zhaoging, Guangdong, China); Wen Zhao (Department of Nephrology, The Second People's Hospital of Futian District Shenzhen, Guangdong, China); Dong Chen (Department of Nephrology, Baoan Central Hospital of Shenzhen, Guangdong, China); Xingming Tang (Haemopurification Department, Tungwah Hospital of Sun Yat-sen University, Dongguan, Guangdong, China); Zhen Ma (Department of Nephrology, Guangzhou Hospital of Integrated Traditional and West Medicine, Guangdong, China); Xianrui Dou (Department of Nephrology, Shunde Hospital of Southern Medical University, Guangdong, China).

\section{Authors' contributions}

Airong Qi, Shunmin Li conceived and designed the research methods. Denggui Luo, Yueming Luo, Yanhong Zou analysed the data. Yuanzhao Xu, Bo Fu, Dong Yang, Jun Yang,Cai Xu and Shuyi Ling collected the data. Denggui Luo, Yueming Luo and Yanhong Zou wrote the original draft. Airong Qi and Shunmin Li reviewed and edited the manuscript. All authors read and approved the final manuscript.

\section{Funding}

This research was supported by Shenzhen Science and Technology Project (JCYJ20190812180603786).

\section{Availability of data and materials}

The datasets used and/or analysed during the current study are available from the corresponding author on reasonable request.

\section{Declarations}

\section{Ethics approval and consent to participate}

Ethics approval was reviewed and approved by the hospital's Human Research Ethics Committee (No. K2020-029-01). The investigator or a person authorized by the investigator was responsible for disclosing the benefits and risks of trial participation to each patient, the patient's legal representative, or a notary witness. Written informed consent was obtained from each patient for participation in the trial. 


\section{Consent for publication}

All of the participants agreed and provided written informed consent.

\section{Competing interests}

The authors declare no confict of interest.

Received: 11 July 2021 Accepted: 6 September 2021

Published online: 13 November 2021

\section{References}

1. GBD Chronic Kidney Disease Collaboration. Global, regional, and national burden of chronic kidney disease, 1990-2017: a systematic analysis for the global burden of disease study 2017. Lancet. 2020;395(10225):709-33. https://doi.org/10.1016/50140-6736(19)32977-0.

2. Peng Y, Ye H, Yi C, Xiao X, Huang X, Liu R, et al. Early initiation of PD therapy in elderly patients is associated with increased risk of death. Clin Kidney J. 2021;14(6):1649-56. https://doi.org/10.1093/ckj/sfaa214.

3. Liyanage T, Ninomiya T, Jha V, Neal B, Patrice HM, Okpechi I, et al. Worldwide access to treatment for end-stage kidney disease: a systematic review. Lancet. 2015;385(9981):1975-82. https://doi.org/10.1016/S0140-673 6(14)61601-9.

4. Wojtaszek E, et al. Uremic toxins, oxidative stress, atherosclerosis in chronic kidney disease, and kidney transplantation. Oxidative Med Cell Longev. 2021;2021:6651367.

5. Chen $\mathrm{R}$, et al. Association of cardiovascular disease with 30-day hospital readmission in Chinese patients receiving maintenance dialysis. Ann Transl Med. 2021;9(8):617. https://doi.org/10.21037/atm-20-2367.

6. Ku E, Mitsnefes MM. Cardiovascular disease in young adults with incident ESRD. Nat Rev Nephrol. 2019;15(7):390-1. https://doi.org/10.1038/s41581-01 9-0154-3.

7. Barbagallo $C M$, Cefalù $A B$, Giammanco A, Noto D, Caldarella R, Ciaccio M, et al. Lipoprotein Abnormalities in Chronic Kidney Disease and Renal Transplantation. Life (Basel). 2021;11(4). https://doi.org/10.3390/life11040315.

8. Keane WF, Tomassini JE, Neff DR. Lipid abnormalities in patients with chronic kidney disease: implications for the pathophysiology of atherosclerosis. J Atheroscler Thromb. 2013;20(2):123-33. https://doi.org/10 5551/jat.12849

9. Provenzano M, Coppolino G, Faga T, Garofalo C, Serra R, Andreucci M. Epidemiology of cardiovascular risk in chronic kidney disease patients: the real silent killer. Rev Cardiovasc Med. 2019;20(4):209-20. https://doi.org/10.31 083/j.rcm.2019.04.548.

10. Lamprea-Montealegre JA, Sharrett AR, Matsushita K, Selvin E, Szklo M, Astor BC. Chronic kidney disease, lipids and apolipoproteins, and coronary heart disease: the ARIC study. Atherosclerosis. 2014;234(1):42-6. https://doi.org/1 0.1016/j.atherosclerosis.2014.02.006.

11. Liang M, Wu Y, Su N, Liu Y, Lin W, Li S, et al. Prevalence, associated factors and cardiocerebral vascular prognosis of anaemia among patients on chronic haemodialysis in South Guangdong, China. J Int Med Res. 2020; 48(11):300060520965791. https://doi.org/10.1177/0300060520965791.

12. Cwiklinska A, et al. Non-HDL-C/TG ratio indicates significant underestimation of calculated low-density lipoprotein cholesterol (LDL-C) better than TG level: a study on the reliability of mathematical formulas used for LDL-C estimation. Clin Chem Lab Med. 2021;59(5):857-67. https://doi.org/10.1515/ cclm-2020-1366

13. Mach F, Baigent C, Catapano AL, Koskinas KC, Casula M, Badimon L, et al. 2019 ESC/EAS guidelines for the management of dyslipidaemias: lipid modification to reduce cardiovascular risk [published correction appears in Eur heart J. 2020 Nov 21;41(44):4255]. Eur Heart J. 2020;41(1):111-88. https:// doi.org/10.1093/eurheartj/ehz455

14. Jacobson TA, Ito MK, Maki KC, Orringer CE, Bays HE, Jones PH, et al. National lipid association recommendations for patient-centered management of dyslipidemia: part 1--full report. J Clin Lipidol. 2015;9(2):129-69. https://doi. org/10.1016/j.jacl.2015.02.003

15. Grundy SM, Stone NJ, Bailey AL, Beam C, Birtcher KK, Blumenthal RS, et al. 2018 AHA/ACC/AACVPR/AAPA/ABC/ACPM/ADA/ AGS/APhA/ASPC/NLA PCNA guideline on the Management of Blood Cholesterol: a report of the American College of Cardiology/American Heart Association task force on clinical practice guidelines [published correction appears in circulation. 2019 Jun 18;139(25):e1182-e1186]. Circulation. 2019;139(25):e1082-143. https:// doi.org/10.1161/CIR.0000000000000625.
16. Ho LT, Lin FJ, Tseng WK, Yin WH, Wu YW, Li YH, et al. On-treatment lipid profiles to predict the cardiovascular outcomes in ASCVD patients comorbid with chronic kidney disease - the multi-center T-SPARCLE registry study. J Formos Med Assoc. 2018;117(9):814-24. https://doi.org/10.1016/j.jfma.2018. 05.020.

17. Foster MC, Coresh J, Hsu CY, Xie D, Levey AS, Nelson RG, et al. Serum betatrace protein and beta2-microglobulin as predictors of ESRD, mortality, and cardiovascular disease in adults with CKD in the chronic renal insufficiency cohort (CRIC) study. Am J Kidney Dis. 2016;68(1):68-76. https://doi.org/10.1 053/j.ajkd.2016.01.015

18. Usui T, Nagata M, Hata J, Mukai N, Hirakawa Y, Yoshida D, et al. Serum nonhigh-density lipoprotein cholesterol and risk of cardiovascular disease in community dwellers with chronic kidney disease: the Hisayama study. J Atheroscler Thromb. 2017;24(7):706-15. https://doi.org/10.5551/jat.37044.

19. NCD Risk Factor Collaboration (NCD-RisC). Repositioning of the global epicentre of non-optimal cholesterol. Nature. 2020;582(7810):73-7.

20. Langsted A, Freiberg JJ, Nordestgaard BG. Fasting and nonfasting lipid levels: influence of normal food intake on lipids, lipoproteins, apolipoproteins, and cardiovascular risk prediction. Circulation. 2008;118(20): 2047-56. https://doi.org/10.1161/CIRCULATIONAHA.108.804146.

21. Ito T, Arima H, Fujiyoshi A, Miura K, Takashima N, Ohkubo T, et al. Relationship between non-high-density lipoprotein cholesterol and the long-term mortality of cardiovascular diseases: NIPPON DATA 90. Int J Cardiol. 2016:220:262-7. https://doi.org/10.1016/i.ijcard.2016.06.021.

22. Boekholdt SM, Arsenault BJ, Mora S, Pedersen TR, LaRosa JC, Nestel PJ, et al. Association of LDL cholesterol, non-HDL cholesterol, and apolipoprotein $B$ levels with risk of cardiovascular events among patients treated with statins: a meta-analysis. JAMA. 2012;307(12):1302-9. https://doi.org/10.1 001/jama.2012.366.

23. Welsh C, Celis-Morales CA, Brown R, Mackay DF, Lewsey J, Mark PB, et al. Comparison of conventional lipoprotein tests and apolipoproteins in the prediction of cardiovascular disease. Circulation. 2019;140(7):542-52. https:// doi.org/10.1161/CIRCULATIONAHA.119.041149.

24. Guo LL, Chen YQ, Lin QZ, Tian F, Xiang QY, Zhu LY, et al. Non-HDL-C is more stable than LDL-C in assessing the percent attainment of non-fasting lipid for coronary heart disease patients. Front Cardiovasc Med. 2021;8: 649181. https://doi.org/10.3389/fcvm.2021.649181.

25. Vega GL, Grundy SM. Current trends in non-HDL cholesterol and LDL cholesterol levels in adults with atherosclerotic cardiovascular disease. J Clin Lipidol. 2019;13(4):563-7. https://doi.org/10.1016/j.jacl.2019.05.012.

26. Cesaro A, Schiavo A, Moscarella E, Coletta S, Conte M, Gragnano F, et al. Lipoprotein(a): a genetic marker for cardiovascular disease and target for emerging therapies. J Cardiovasc Med (Hagerstown). 2021;22(3):151-61. https://doi.org/10.2459/JCM.0000000000001077.

\section{Publisher's Note}

Springer Nature remains neutral with regard to jurisdictional claims in published maps and institutional affiliations.
Ready to submit your research? Choose BMC and benefit from:

- fast, convenient online submission

- thorough peer review by experienced researchers in your field

- rapid publication on acceptance

- support for research data, including large and complex data types

- gold Open Access which fosters wider collaboration and increased citations

- maximum visibility for your research: over $100 \mathrm{M}$ website views per year

At BMC, research is always in progress.

Learn more biomedcentral.com/submissions 